\title{
ADAPTASI PT. FREEPORT INDONESIA TERHADAP BUDAYA LOKAL PAPUA YANG TERSAJI DALAM KONSEP VISUAL BRANDING PERUSAHAAN
}

\author{
Nurita Ririh Pratiwi \\ Mahasiswi Program Studi Pasca Sarjana Seni Rupa \\ Universitas Sebelasmaret Surakarta \\ nuritaririhpratiwi@yahoo.com
}

\begin{abstract}
Branding in a company requires workmanship is not easy to maintain consistency of quality in each element, it will created a valuable visual work. Value here is meant value that not only communicate information about the company with public, but also the value of its own visual work in view of the visible combination of its various elements. This research will analyze the branding strategy of a foreign company, PT Freeport Indonesia, which adapts the elements of local Papuan culture as a concept to each of its branding. Company data is neatly wrapped with local Papuan cultures into treats that are not monotonous, not frontal, and more able to establish kindship between the company and the surrounding local society. In addition, also to know the function of the application of local cultural content of Papua presented in a new form, namely PTFI visual branding.

Viewed from the point of view of art philosophy, which in the science of art philosophy there is a study of the elements underlying the creation of a work of art. Artwork here is a series of Visual Branding PTFI which seems to have value and meaning, there are elements of artists, elements of the work itself, and elements of society that act as public art, together to form a formation with a particular purpose, has created a blend of visual works of character and has an aesthetic value.
\end{abstract}

Keyword: Art, Local Papuan Culture, Visual Branding.

Relevance to Visual Communication Design Practice: Provides an inspiration for a more valuable visual branding design while still running its main function as visual communication and self-image to around, one of which is by raising the local culture in the region.

\section{PENDAHULUAN}

Menurut Jacob Sumardjo dalam Filsafat Seni (2000: 27) diterangkan, bahwa setiap karya seni itu sedikit banyak mencerminkan setting masyarakat tempat seni itu diciptakan. Secara tidak langsung, seorang seniman yang hidup dalam suatu masyarakat tertentu akan dididik oleh keadaan atau iklim seni di daerah tersebut. Seniman memahami dan menguasai nilai seni dan nilai-nilai lain dalam masyarakat. Pendidikan seni yang didapat langsung dari masyarakat itulah yang mempengaruhi proses penciptaan karya seninya. Sebelum menjadi seorang seniman, seniman adalah bagian dari masyarakat. Melaui proses alamiah tadi seorang masyarakat belajar dan mengembangkan kemampuan berkeseniannya sehingga kemampuannya diketahui, dihargai, dan pada akhirnya mendapat pengakuan dari masyarakat itu sendiri. Dalam konteks lain, seni dapat membentuk manusia dan masyarakat dengan cara yang berbeda, yakni dengan cara ilmu dan teknologi. Ilmu yang membuat manusia berfikir lebih baik dan 
belajar untuk menemukan sesuatu dan mewujudkannya menjadi sebuah karya atau benda seni yang bernilai, salah satunya adalah sebuah seni yang tertuang dalam konsep visual branding PT. Freeport Indonesia.

Pada umumnya, sebuah perusahaan akan mempunyai sistem komunikasi kepada publik untuk memperkenalkan diri dan produknya, salah satunya melalui visual branding, yaitu kegiatan menciptakan pesan tampilan produk yang dihasilkan perusahaan kepada konsumen secara visual, sebagai pesan perusahaan yang menghasilkan produk dengan kualitas yang baik, dan memberikan rasa nyaman, aman dan rasa bersahabat (Sutherland,Max. 2005 : 97). PT. Freeport Indonesia sendiri merupakan perusahaan afiliasi dari Freeport-McMoRan. PTFI menambang, memproses dan melakukan eksplorasi terhadap bijih yang mengandung tembaga, emas dan perak. Beroperasi di daerah dataran tinggi di Kabupaten Mimika Provinsi Papua, Indonesia. Dan memasarkan konsentrat yang mengandung tembaga, emas dan perak ke seluruh penjuru dunia, diluar Indonesia.

Dapat dikatakan, masyarakat luas di seluruh Indonesia akan mengetahui profil singkat perusahaan ini dengan garis besar eksploitasi di tanah Papua. Lekatnya PTFI dengan pandangan eksploitasi di tanah Papua ini lah yang menjadi misi tersendiri bagi PTFI untuk bekerja keras dalam membangun citra PTFI yang lebih dapat diterima dengan baik dan menyampaikan keuntungan jika menjalin hubungan baik dengan perusahaan ini. Ketepatan agenda dan kecermatan menentukan kegiatan dan juga mengangkat budaya-budaya lokal Papua dalam brandingnya menjadikan PTFI mampu menyatu dengan masyarakat sekitar dan menjadi sebuah simbiosis yang saling menguntungkan. Eksplorasi budaya dan kearifan lokal selalu menjadi headline dalam sistem visual branding PTFI ini. Lain halnya dengan perusahaan-perusahaan industri selain PTFI, yang sering kali hanya mengangkat tentang seputar profil perusahaan, tanpa menampilkan hal-hal yang bersifat kearifan lokal sekitar perusahaan beroperasi.

Kejelian mengangkat isu-isu yang sedang hangat beredar dalam manyarakat, strategi komunikasi yang tepat dan efektif kepada masyarakat sekitar, yang pada umumnya masih memiliki latar belakang pendidikan rendah, menjadi prestasi dan catatan penting tersendiri PTFI di mata penulis. Hal inilah yang menggugah penulis untuk ingin mengkaji lebih dalam kejelian dan kecermatan PTFI dalam memasukan unsurunsur budaya lokal di setiap visual branding perusahaan sebagai upaya menciptakan dan memelihara hubungan baik antara perusahaan dengan negara yang terkait kontrak kerjasama pada umumnya, dan masyarakat sekitar pada khususnya

Kajian ini menjadi sangat menarik, ketika penulis kerap kali menemukan unsurunsur budaya lokal yang membalut setiap karya visual branding PTFI. Kekayaan budaya lokal Papua tersaji dengan rapi dan apik, terkolaborasi membentuk kesatuan yang mampu mengkomunikasikan PTFI kepada masyarakat luas di sekitar wilayah operasional perusahaan. Melalui pisau bedah buku karya Bapak Jakob Sumardjo, penulis akan mencoba menjabarkan unsur-unsur seni yang melatarbelakangi dan terkandung dalam setiap karya, baik dari segi pencipta karya 
(seniman), karya itu sendiri (seni), dan publik seni yang menjadi target karya ini dikomunikasikan, sehingga akan menjawab rumusan masalah sebagai berikut : Bagaimana balutan budaya lokal Papua itu dapat tersaji dengan baik dalam visual branding PTFI, ditelaah dari sudut pandang filsafat seni?

\section{METODE PENELITIAN}

Metode penelitian yang digunakan dalam penelitian ini adalah metode kualitatif. Menurut Bogdan \& Taylor (1992: 21-22) Metode kualitatif adalah salah satu prosedur penelitian yang menghasilkan data deskriptif berupa ucapan atau tulisan dan perilaku orang-orang yang diamati. Penelitian ini mencoba untuk mendeskripsikan produk visual branding yang dibuat oleh PT. Freepot Indonesia. Lokasi penelitian dilakukan di Timika Papua dan Kantor Delegasi PTFI di Kuningan, Jakarta. Waktu penelitian dilakukan selama 5 bulan dengan pecarian data di Timika, Papua dan 2 hari di kantor Jakarta.

Data penelitian ini berupa observasi langsung di lokasi, wawancara langsung dengan para narasumber yang berkompeten, foto-foto hasil karya visual branding PTFI, dan beberapa wacana dari studi pustaka yang terlait.

\section{HASIL DAN PEMBAHASAN}

Balutan Budaya Lokal Papua

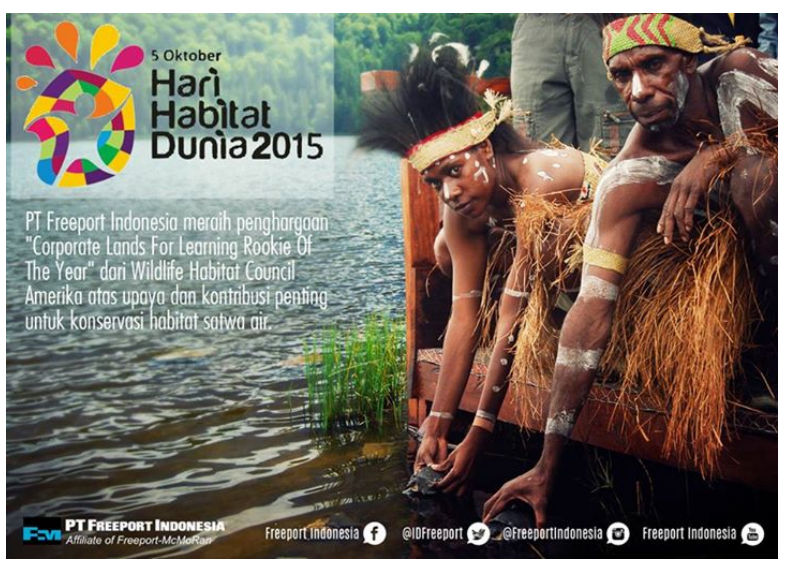

Gambar 1 Poster Hari Habitat Dunia 2015 oleh PTFI

Sumber : @freeportindonesia, web resmi PTFI

\section{Papua adalah}

sebuah provinsi terluas Indonesia yang terletak di bagian tengah Pulau Papua atau bagian paling timur West New Guinea (Irian Jaya). Belahan timurnya merupakan negara Papua Nugini atau East New Guinea. Nama provinsi ini diganti menjadi Papua sesuai UU No. 21 Tahun 2001 tentang Otonomi Khusus Papua. Pada 2003, disertai oleh berbagai protes (penggabungan Papua Tengah dan Papua Timur), Papua dibagi menjadi dua provinsi oleh pemerintah Indonesia, bagian timur tetap memakai nama Papuasedangkan bagian baratnya menjadi Provinsi Irian Jaya Barat (setahun kemudian menjadi Papua Barat). Bagian timur inilah yang menjadi wilayah Provinsi Papua pada saat ini. Kata Papua sendiri berasal dari bahasa melayu yang berarti rambut keriting, sebuah gambaran yang mengacu pada penampilan fisik sukusuku asli di Papua. 
Terdapat beragam suku dan peradaban di kawasan Papua, mengingat letak geografisnya yang membentang luas dan tersekat-sekat oleh pegunungan, maka tidak heran jika disetiap wilayah memiliki adat istiadat, kesenian, dan juga kerajinan tangan masing-masing. Kemurnian adat dan budaya masih sangatlah terjaga mengingat belum banyaknya modernisasi yang memasuki kawasan ini. Mulai dari Tradisi Sagu, Tradisi potong Jari, Tradisi Perkawinan, Tradisi Pernikahan, Tradisi Tari-tarian, sampai dengan Tradisi Perang Suku tersaji di Papua.

PTFI memanfatkan keadaan ini sebagai alternatif menumbuhkan nilai estetika dalam setiap karya visualnya, sehingga terkomunikasikan seolah-olah tidak hanya tentang perusahaan semata, namun juga terdapat unsur-unsur lain yang mampu mengambil hati para peminat karyanya. Tersiratkan sebuah persodaraan yang erat antara perusahaan dengan masyarakat sekitar, terutama adat-istiadan dan keseniannya. Hal inilah yang kerap kali meredam dan menjadi solusi di setiap konflik yang terjadi antara perusahaan dengan masyarakat sekitar. Unsur-unsur kearifan lokal yang ada akan diseleksi dengan baik, kemudian dikemas dengan rapi sehingga kearifan lokal Papua akan membalut karya visual ini dengan baik, dan disuguhkan dalam tampilan baru.

\section{Transformasi Unsur-unsur Filsafat Seni}

\section{Dalam Karya Visual PTFI}

Menurut Jakob Sumardjo (2000: 32), Filsafat seni yang merupakan bagian dari estetika modern, tidak hanya mempersoalkan karya seni atau benda seni (hasil atau produk), tetapi juga aktifitas manusia atas produk tersebut, baik keterlibatannya dalam proses produksi maupun caranya mengevaluasi dan menggunakan produk tersebut. Ada tiga pokok persoalan filsafat seni, yakni seniman atau kreator sebagai penghasil seni, karya seni atau benda seni, dan penikmat seni atau apresiator.

\section{Seniman}

Setiap karya seni muncul dari seorang seniman, apakah karya seni itu berbobot, kurang berbobot, atau seni kelas bawah pasti muncul dari seorang seniman. Beberapa persoalan yang sering muncul terkait seniman dengan karyanya adalah kreatifitas dan ekspresi. Seniman menekankan pada aspek ekspresi, kreasi, orisinalitas, intuisi, imajinasi, ide, konsep, keterampilan dan referensi Jakob Sumardjo (2000: 49).

Tampak dalam setiap karya visual branding PTFI, sang pencipta karya telah mengusung misi khusus dan tujuan tersendiri. Mencari ide segar, mengangkat issu-issu hangat yang sedang berkembang menjadi ciri khas cara kerja sang pencipta karya ini. Meskipun dalam pengerjaannya terdapat unsur alasan klasik yaitu tuntutan materi, namun sang seniman selalu menyeimbangkan nilai-nilai estetika dalam karyanya, sehingga karya yang tercipta akan tetap menjalankan tugasnya, dengan tetap memiliki nilai estetika di dalamnya. Kreatifitasnya terus diasah dan dimainkan ditengah-tengah idealisme berkeseniannya, tanpa menjatuhkan pihak lain. Balutan budaya lokal Papua dikemas menjadi suguhan utama yang melandasi trending topic yang hendak perusahaan sampaikan. 


\section{Karya Seni/Benda Seni}
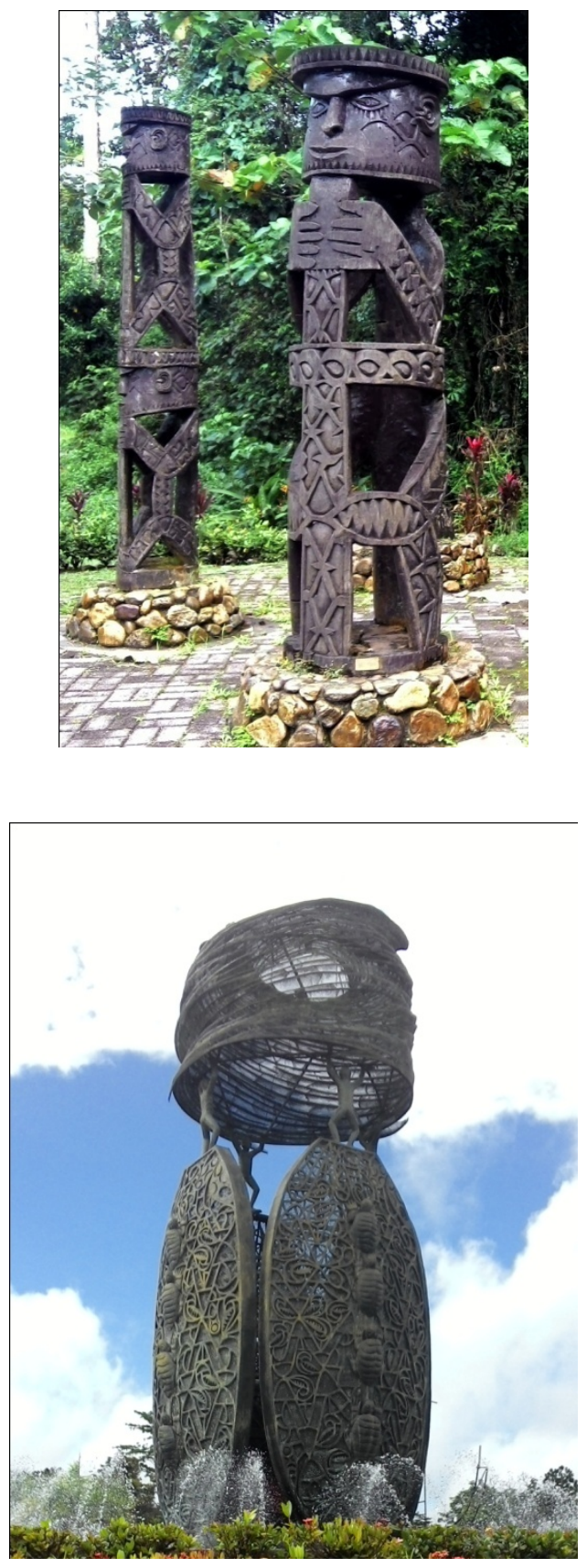

Gambar 2 Monumen "Selamat Datang” yang terdapat di kantor pusat PTFI, Mimika, Papua. Sumber : Foto oleh penulis

Karya seni adalah hasil proses kreasi seniman berwujud visual dua dimensi maupun tiga dimensi (Seni rupa, patung, lukis, desain, arsitektur), wujud audio (music dan sastra), audio visual (Film, teater, seni tari) yang dapat dinikmati atau diapresiasi melalui berbagai indra yang dimiliki oleh manusia. Benda seni atau karya seni terkait erat dengan medium atau bahan yang digunakan dalam menciptakan karya seni tersebut, Jakob Sumardjo (2000: 17) .

Mulai dari karya cetak berupa ragam poster dalam tiap-tiap event-nya, cindera mata untuk para tamu kehormatan, perlengkapan pakaian dan atribut lainnya, majalah bulanan, tampilan pada website, kartu undangan, hingga gapura-gapura dan monumen pada bundaran, selalu terbalut apik dengan budaya lokal papua. Terdapat pendekatan dan penelitian yang mendalam dalam setiap karya seninya, dalam upaya memahami dan mengaplikasi budaya lokal Papua untuk dapat ditampilkan secara bersamaan dengan setiap misi yang diusung perusahaan. Sebuah kolaborasi dari unsur yang mengadaptasi kenyataan yang ada dengan ekspresi jiwa seniman, yang tetap mempertimbangkan aspek bentuk, material, struktur, simbol dan estetika.

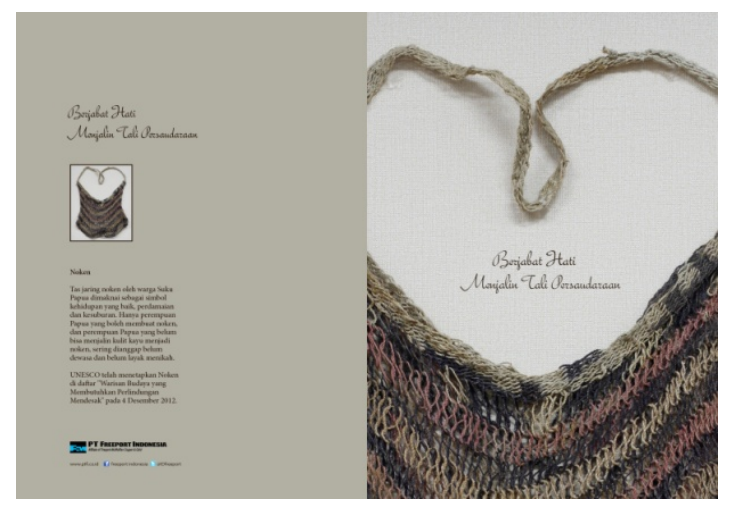




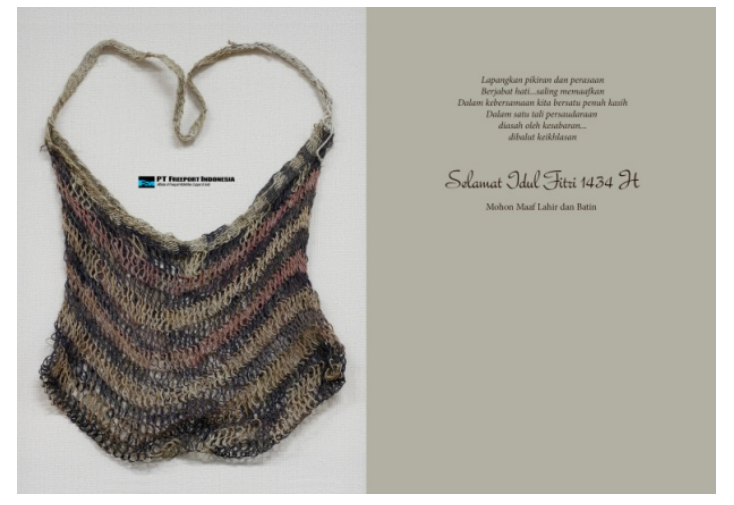

Gambar 3 Kartu lebaran PT. Freeport Indonesia, bagian luar dan dalam kartu, yang menggunakan tas khas Papua bernama Noken, dikolaborasikan dengan teknik fotografi produk dan tata letak typografi Sumber : Dokumentasi Divisi Corp. Comm. PT. Freeport Indonesia
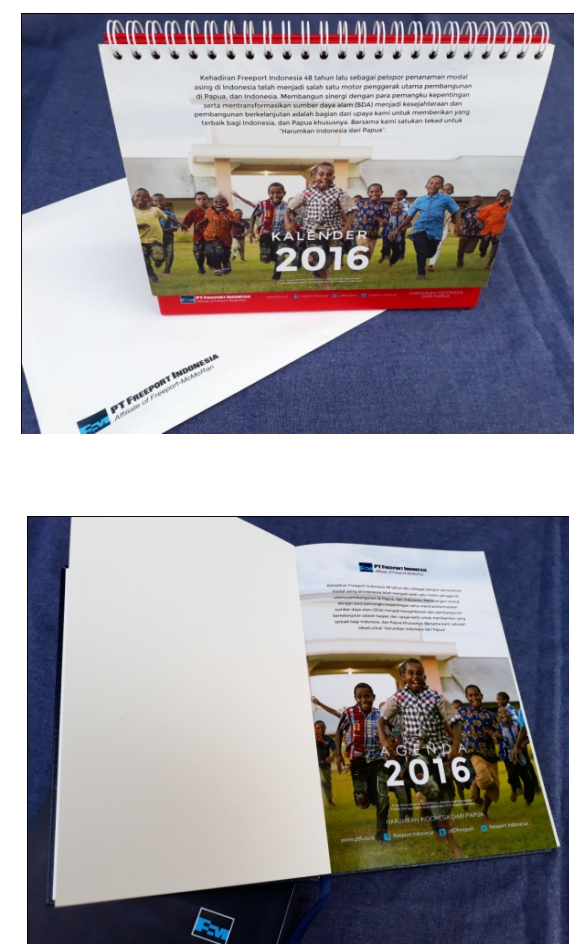

Gambar 4 Merchandise berupa kalender meja dan buku agenda tahunan dengan tema "Harumkan Indonesia dari Tanah Papua”, mengkolaborasika teknik fotografi jurnalistik dengan tata letak typografi dalam desain.

Sumber : Dokumentasi pribadi penulis.

\section{Publik Seni/Apresioator}

Publik seni adalah masyarakat luas yang berasal dari latar belakang sosial dan ekonomi berbeda. Publik seni penting sebab seni bukan hanya masalah seniman dan karya seninya, melainkan bagaimana karya seni dapat berkomunikasi atau berdialog dengan orang lain. Agar karya seni dapat berdialog secara baik dengan masyarakatnya, maka diperlukan seorang kurator atau kritikus yang menjelaskan secara lebih obyektif tentang struktur estetika dan makna sebuah karya seni.

Seorang seniman disebut seniman oleh masyarakatnya sebab status yang diperjuangkannya. Walaupun tidak seluruh masyarakat dapat diklaim sebagai publik seni, namun sebagian besar masyarakat yang pernah dan berkeinginan menikmati karya seni dapat menjadi bagian dari publik seni. Publik seni tertentu seperti kolektor dan para konsumen seni sangat berperan dalam menentukan status dan kelas dari seorang seniman. Publik seni menekankan pada aspek apresiasi, interpretasi, evaluasi, konteks, pengalaman, pengetahuan, penghargaan, dan respon dari publik.

Apresiasi yang paling menonjol dalam setiap karya visual PTFI ini adalah dengan besarnya minat kunjung di area monumen atau event yang diselenggarakan, sebagai simbol mereka telah mengunjungi Bumi Cendrawasih, Papua.

\section{Aplikasi Seni Sebagai Benda Dalam Visual Branding PTFI}

Dalam seni rupa, penggolongan seni secara umum dibagi menjadi dua, seni murni (pure art/fine art) dan seni pakai (applied 
Art). Pure Art atau seni murni adalah seni yang diciptakan semata-mata untuk dinikmati estetika dan keindahannya, misalnya lukisan, patung, seni grafis, seni pahat, seni musik, seni balet dan beragam seni lainnya yang dibuat tanpa adanya unsur fungsional yang langsung berhubungan dengan fisik manusia. Jenis seni seperti ini pada saman yunani romawi digolongkan sebagai seni halus atau istilah Sanento Yuliman sebagai seni rupa atas. Menurut Jakob Sumardjo (2000: 88), seni semacam ini digolongkan sebagai seni besar (major art) sebab dianggap sebagai seni bagi kaum yang merdeka. Para pencipta dari jenis seni inilah yang diklaim sebagai seniman.

Sedangkan applied art atau seni pakai adalah seni yang diciptakan dengan tujuan agar memiliki fungsi secara langsung bagi kehidupan manusia, disamping itu juga memiliki estetika sebagai penunjang. Sebagian karya Applied art kemudian berkembang dengan istilah desain, dimana tuntutan kebutuhan masyarakat atas jenis seni ini yang semakin tinggi sehingga aspek komersialisasinya dapat memberi jaminan kesejahteraan yang lebih baik bagi para kreatornya atau desainernya.

Dalam pengamatan dari beberapa karya visual yang telah tercipta, visual branding PTFI ini tergolong dalam seni pakai atau applied art. Karena tujuan utama penciptaan karya adalah merupakan pemenuhan terhadap misi tertentu, tidak hanya ekspresi jiwa pencipta karya semata. Terdapat banyak unsur dan aturan yang mengikat seniman dalam pembuatan karya ini, kapitalisasi ide dan konsep memang mendominasi, namun sang seniman tetap mampu menjaga keseimbangan estetika karyanya yang mungkin menemui berbagi kendala.

Setiap karya diciptakan dengan ukuran, bentuk, warna, material dan kegunaan yang berbeda-beda. Tidak dipungkiri, terciptanya karya akan terus ada seiring dengan kebutuhan perusahaan dalam mengkomunikasikan dirinya dengan publik yang menjadi sasaran karya visualnya.

\section{KESIMPULAN}

Kebutuhan mengkomunikasikan sebuah perusahaan melalui karya visual sudah kerap kali dilakukan. Salah satunya dengan terus memaparkan profil diri sebagai pencitraan yang baik dan memikat. Berbagai teknik penciptaan karya banyak dilakukan, sebagaimana oleh PTFI yang mengkonsep visual branding-nya dengan balutan budaya lokal Papua, yaitu budaya lokal tempat perusahaan ini beroperasi, dengan tujuan mampu menjalin keakraban dan kekerabatan antara perusahaan dengan masyarakat sekitarnya.

Terciptanya sebuah karya akan terdapat banyak unsur yang melatarbelakanginya. Sebagaimana karya visual branding PTFI yang tampak memiliki nilai dan makna dalam balutan budaya-budaya lokal Papua-nya. Unsur seniman, unsur karya itu sendiri, dan unsur masyarakat luas yang berperan sebagai publik seni, menyatu membentuk formasi dengan mengusung tujuan tertentu, telah menciptakan perpaduan karya visual yang berkarakter dan memiliki nilai estetika.

Tentu membutuhkan pengerjaan yang tidak asal-asalan dan tetap menjaga konsistensi mutu di tiap-tiap unsurnya, maka akan melahirkan karya visual yang bernilai. Nilai disini dimaksudkan nilai yang lebih dari 
hanya sekedar mengkomunikasikan informasi tentang perusahaan dengan masyarakat, namun juga menjadi nilai karya visual tersendiri ditinjau dari tampaknya ekspresi jiwa seniman di setiap karyanya. Data perusahaan terbalut rapi dengan budayabudaya lokal Papua menjadi suguhan yang tidak monoton, tidak frontal, dan lebih dapat menjalin kekerabatan antara perusahaan dengan masyarakat sekitar.

\section{DAFTAR PUSTAKA}

[1] Andrianto, Taufik Tuhana. 2001. Mengapa Papua Bergolak?. Gama Global Media : Yogyakarta.

[2] Danesi, Marcel. 2004. "Pesan, Tanda, dan Makna :Buku Teks Dasar Mengenai Semiotika dan Teori Komunikasi". Yogyakarta : Jalasutra.

[3] Muller, Kal. 2008. Mengenal Papua. Jakarta : Daisy World Book.

[4] Sutherland, Max. 2005. Advertising And The Mind of The Consumer. Jakarta : PT Gramedia Pustaka Utama.

[5] Sugiharto, Bambang. 2014. "Untuk Apa Seni?”. Bandung : Matahari.

[6] Sumardjo, Jakob. 2000. Filsafat Seni. Bandung:ITB.

[7] http://www.PTFI.co.id 